\title{
Preduodenal Portal Vein or Malrotation
}

\author{
Nisar Ahmad Bhat ${ }^{*}$, Shadab Nabi Wani* ${ }^{* *}$ Imtiaz wani"*, Syed abeer** \\ Department of Pediatric Surgery, Sheri Kashmir Institute of Medical Sciences Srinagar Kashmir, India.
}

\section{A B STRACT}

Preduodenal portal vein (PDPV) is a rare congenital anomaly and occurs either as a single malformation or in association with other malformations. PDPV is mainly asymptomatic and associated intestinal anomalies are often more likely to cause high intestinal obstruction. A neonate with recurrent bilious vomiting since birth is presented. Laparotomy revealed PDPV but it was intestinal malrotation that was causing intestinal obstruction.

Key words: Duodenal obstruction, preduodenal vein, malrotation

\section{INTRODUCTION}

Preduodenal portal vein was first described by knight in $1921,{ }^{1}$ with an incidence of about 1 in $10000 .{ }^{2}$ Most common cause of duodenal obstruction is duodenal atresia. ${ }^{3}$ Other causes are annular pancreas, Ladd's band and malrotations. PDPV is one of the rare causes of duodenal obstruction. In a large series of patients with congenital duodenal obstructions, PDPV was found in only $4 \%$ case. $^{3}$ PDPV was not exactly the cause of duodenal obstruction in majority of these cases, the obstruction was caused by associated anomalies such as duodenal diaphragm, intestinal malrotation and annular pancreas.

\section{CASE REPORT}

A 7- day old male baby with birth weight of $2.7 \mathrm{~kg}$ was admitted with bilious vomiting that started within few hours of first feed after birth. Patient was admitted immediately in other hospital where babies was managed on Nasogastric aspiration and intravenous fluids for 2 days and was send home without further evaluation. After few feeds patient again had bilious vomiting. Baby had tachycardia with mild dehydration. General physical examination was normal and upper abdomen was distended. We stabilized the baby with nasogastric tube and intravenous fluids. Gastric aspirate

Address for correspondence:

E-mail: nisarabuhade@yahoo.com

DOI: 10.5530/ijmedph.2.2011.11 was bilious. X-ray abdomen showed two big gas shadows in the upper abdomen suggestive of duodenal obstruction. Upper GI contrast study was done that showed dilated stomach and duodenum with a delayed passage of contrast in the small bowel. After stabilization laparotomy was done that showed preduodenal portal vein (Figure 1).Stomach was distended and the duodenum distal to PPDV was also distended. We also found associated malrotation of entire bowel that was responsible for the obstruction (Figure 2). Ladd procedure for done for the correction of malrotation and we also performed duodeno-duodenostomy anterior to portal vein. Orals started on $5^{\text {th }}$ postoperative day were tolerated well and was discharged home on $8^{\text {th }}$ POD. Baby is doing well on follow up.

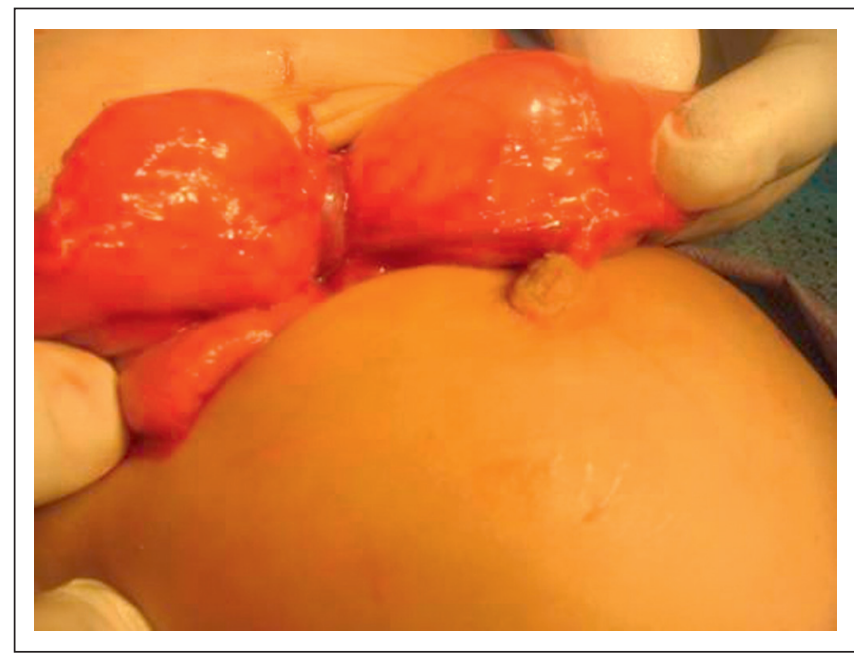

Figure1: Dilated stomach and duodenum with Preduodenal portal vein (PDPV). 


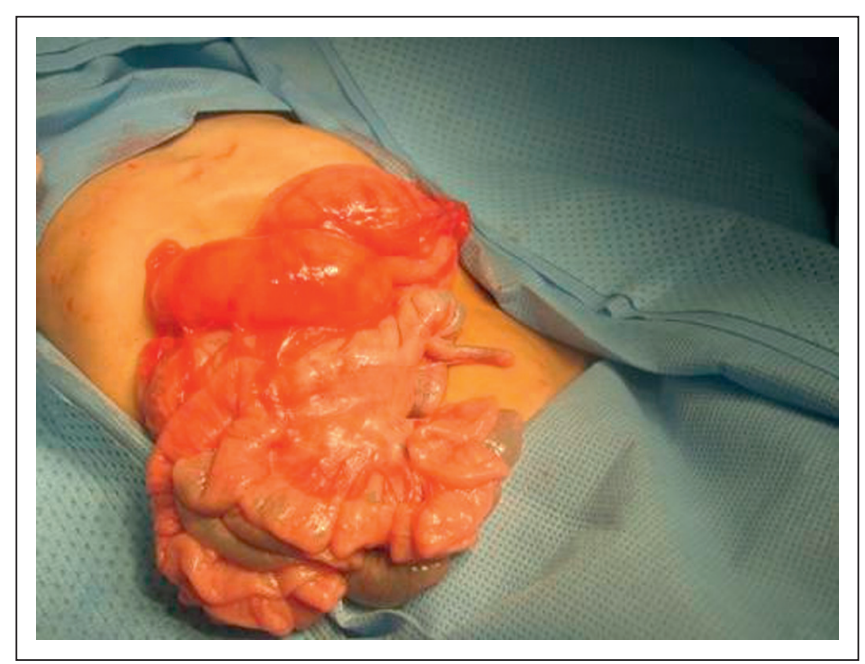

Figure 2: Free floating caecum with narrow mesentery.

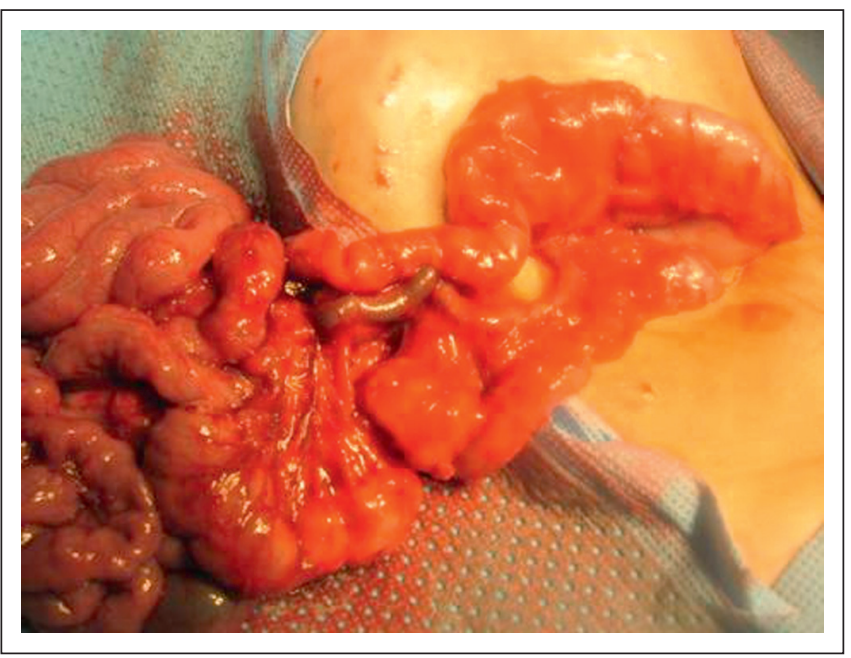

Figure 3: Duodenoduodenostomy and correction of malrotation

\section{DISCUSSION}

Developmentally, primitive vitelline vein that forms portal vein passes in front of duodenum and pancreas rather than passing inferior and behind the pancreas on its cephalad path to liver. ${ }^{2}$ In general, PDPV without associated anomalies may be the cause of duodenal obstruction in the first or second portion if symptoms related to PDPV occur. ${ }^{1,4,5,6}$ However it is not common for obstruction to be due to extrinsic pressure of the preduodenal portal vein on the bowel. Rather it has been due to associated anomalies such as duodenal diaphragms, duodenal colic bands, malrotation, or annular pancreas.

Other associated anomalies with PDPV, include some features of polysplenia syndrome in $75 \%$ cases, ${ }^{7}$ biliary atresia in $5-10 \%$ cases. $^{2}$ Association of preduodenal common bile duct have also been repoted. ${ }^{8}$
Diagnosis of PDPV as a cause of duodenal obstruction has been picked up on antenatal ultrasonography as evident from the association of polyhydromnias with dilated fluid filled stomach and duodenum appearing as a double -bubble. ${ }^{9}$ PDPV may lead either to complete or partial duodenal obstruction but may go unrecognized in childhood manifesting later in adult life. It may occasionally be an incidental finding. Only in about 10 cases duodenal obstruction could be confidently described as being due to a PDPV. ${ }^{7}$ Chacteristic presentation of a complete duodenal obstruction from what ever cause is vomiting within few hours of birth and intolerance of attempted feeding. Abdomen roentgenogram showing double-bubble appearance is often enough to diagnose this entity. ${ }^{3}$ However, Partial obstruction usually results in recurrent episodes of vomiting, failure to thrive, and aspiration over a period of months to years. Patients with symptoms of partial obstruction should undergo an upper gastrointestinal contrast study. ${ }^{3}$ Some cases are not recognized until adult life and may present with gastric outlet obstruction later in the life. ${ }^{6}$ PDPV may be an incidental finding in an adult at the time of cholecystectomy. ${ }^{2}$

Since all the cases of duodenal obstruction require laparotomy, it is not mandatory to diagnosis PDPV preoperatively but its recognition during surgery is important as it might not be the cause of obstruction as was seen in our case. Operative finding of distended duodenum distal to PDPV made us to look for some other cause and it was malrotation. One has to be careful during surgery about the complications including iatrogenic hemorrhage from abnormal vein or damage to the biliary tract or the distended duodenum. $^{2}$

Although congenital duodenal obstruction is a relative surgical emergency, the patient should not be rushed to the operating room until the baby is stable. During surgery definitive cause for the obstruction must be identified and managed accordingly. In our case we performed the Ladd procedure for associated malrotation and loose over bridging duodenoduodenostomy in order to avoid the compression of the portal vein, as has been recommended in recent studies. ${ }^{10}$ Recurrence of the disease in the next offsprings is a probability because the animal models in rats have suggests autosomal recessive inheritance transmission of the PDPV. ${ }^{11}$

\section{REFERENCES}

1. Knight $\mathrm{HO}$. An anomalous portal vein with its surgical dangers. Ann Surg 1921; 74:697-699.

2. D.Pathak and Y.K.Sarin. Congenital duodenal obstruction due to a preduodenal portal vein. Indian Journal of Pediatrics 2006; 73:423-425.

3. Grosfeld JL, Rescorla FJ. Duodenal atresia and stenosis: reassessment of treatment and outcome based on antenatal diagnosis, pathologic variance, and long- term follow up. World J Surg 1993:17:301-309. 
4. Choi SO, Park WH, Preduodenal portal vein: A cause of prenatally diagnosed duodenal obstruction. Pediatr Surg 1995; 30:1521-1522.

5. Talus H, Roohipur R, Depaz H, Adu AK, Preduodenal portal vein causing duodenal obstruction in an adult.J Am Coll Surg 2006; 202:552-553.

6. John AK, Gur U, Aluwihare A, Cade D. Pre duodenal portal vein as a cause of duodenal obstruction in an adult. ANZ J Surg 2004; 74:1032-1033.

7. Georgacopulo P, Vigi V. Duodenal obstruction due to a preduodenal portal vein. J Pediatr Surg 1980; 15:339-340

8. Yi SQ, Tanaka S, Tanaka A, Shimokawa T. An extremely rare inversion of the preduodenal portal vein and common bile duct associated with multiple malformations. Report of an adult cadaver case with a brief review of the literature. Anat Embryol (Berl) 2004; 208:87-96.

9. Choi So, Park WH. Preduodenal portal vein: a cause of prenatally diagnosed duodenal obstruction. J Pediatr Surg 1995; 30(10):1521-2.

10. Ohno AK, Nakamura T, Azuma T. Evaluation of the portal vein after duodenoduodenostomy for congenital duodenal stenosis associated with the preduodenal superior mesenteric vein, situs inversus, polysplenia and malrotation. J pediatr Surg 2007; 42:436-439.

11. Nakajima H, Li L, Nomura T. Anomalous (Preduodenal) portal vein autosomal recessive mutation in AKR/J mice Comp Med 2001; 51:22-52. 